\title{
Pulping of Sugarcane Bagasse Using Ceriporiopsis subvermispora SS-33 and Ophiostoma piliferum as a Fungal Bio-agents
}

\author{
Rawia F. Gamal ${ }^{\#}$ Hemmat M. Abdelhady, Zenat A. \\ Nageeb* and Enas A. ELgarhy* \\ Dept. of Microbiology, Fac. Agric., Ain-Shams Univ. and \\ *Cellulose and Paper Department, National Research Center, \\ Cairo, Egypt.
}

B AGASSE is an agricultural by product from sugar cane after the cane is harvested and crushed to extract the juice. The utilization of bagasse as raw material for pulp and paper industry is increasing rapidly which also increasing pollution to the environment. In renewable resource to reduce chemical pollution, white rot fungi or lignin-degrading fungi was employed to contribute to remove lignin from raw materials. The aim of this investigation, is to determine the activity of white-rot fungi on bagasse as in in vivo biopulping or pretreatment by comparing the lignin content of bagasse before and after the biodegradation in different conditions. It was found that the most favorable conditions for bagasse pulping can be achieved by treatment with propylene glycol (PG) $90 \%$ under pressure for $1 \mathrm{~h}$ or without pressure for $2 \mathrm{~h}$ at the cooking temperature $150^{\circ} \mathrm{C}$. The mentioned treatments gave high pulp yield, with no rejects and low kappa number. The extractive removal of bagasse (10 mesh) by steam resulted to high weight loss, acid perceptible polymeric lignin (APPL) production and low kappa number. The biological 4 weeks treatment of bagasse by Ophiostoma piliferum at $27^{\circ} \mathrm{C}$ increased the brightness, breaking length and tear factor of unbleached bagasse paper sheets, when compared with steam treatment. Using mixed culture of Ceriporiopsis subvermispora and O. piliferum either from one or twostage cultures for extractive removal and biodegradation of bagasse, led to the improvement the chemical pulp composition and the properties of unbleached paper sheets. One stage culture treatment increased the unbleached paper sheets properties which expressed as brightness, breaking length and tear factor by $5.6 \%, 0.08 \mathrm{~km}$ and 3.78 , compared with the two-stage culture treatment results, which were $3.08 \%, 21.41 \mathrm{~km}$ and 3.69 , respectively. The mentioned results were more convenient when compared with steam extraction method. Scanning electron micrographs (SEM) revealed that the biological fibers of the produced paper sheets exhibit a cleaner surface, high flexibility and conformability, which would be contributed to the good bonding nature.

\footnotetext{
\#Corresponding author mailing address: Dept. of Agricultural Microbiology, Faculty of Agriculture, Ain Shams University, Shoubra El-Kheima, 11241, Cairo, Egypt.

E-mail : $\underline{\text { Rawiagamal123@gmail.com }}$
} 
Keywords: Biopulping, Ceriporiopsis subvermispora, Ophiostoma piliferum, Sugarcane bagasse, Kappa no, Propylene glycol pulping.

In the field of chemical technology, where manufacture of a variety of products on large scale has resulted in serious effluent and hazardous waste disposal problems, the need for safer and 'environmental friendly' technologies has become imminent. This has resulted in scientists attempting to learn from natural processes, and therefore a new aspect of microbiology and biotechnology has rapidly begun to gain ground. Microorganisms perform their myriads of biochemical reactions under ambient conditions with little or no toxic and hazardous by-products. Therefore microbial enzymes alternatives to polluting chemical technologies, which began initially as an idea, have reached realistic proportions whereby they can be considered as worthwhile and practical technologies of the future. A glimmer of hope to save the environment and yet achieve the goals of chemical technology is gaining momentum in several frontier developments in this area. One such area is the pulp and paper industry where the quantities of bagasses as raw material processed are huge, as well as the use of naturally hazardous chemicals are also large in Egypt. Progress through intense research and development activities to make the technology eventually totally free from hazardous chemicals would be a cherished dream come true. In the present article, an overview is presented on the present status and future prospects on the use of white- rot fungi as effective bio-reagents to achieve biobleaching in place of poisonous chlorine compounds conventionally used to achieve pulp brightness of a high order in the manufacture of high-quality paper products.

Sugarcane bagasse is an agricultural waste abundant in several countries. The possibility of using bagasse pulps for the production of newsprint was studied as far back as 1950 (Goncalves et al., 2008). Biopulping can be defined as the biological pretreatment of wood chips followed by mechanical or chemical pulping processes. Ceriporiopsis subvermispora is one of the most suitable white-rot fungi for the biopulping process. Wood pretreatment with such fungus leads to a reduction of energy consumption during mechanical pulping by at least $30 \%$. Fungal pretreatment also provide an increase in delignification rate of acid sulfate and bisulfite pulping as well as in organosolv pulping processes such as formic acid/acetone and methanol/water pulping (Ferraz et al., 2000a). This increased delignification rates permitted preparation of biopulps in shorter cooking times, resulting in energy saving and increased digester throughout. In addition, biopulps obtained by formic acid/acetone pulping of pinus radiate biotreatment with Ceriporiopsis subvernispora has increased tensile strength (Ferraz et al., 2000b). Moreover, the pretreatment with the species Ophiostoma piliferum, had superior abilities for removing pitch from wood which produced in large concentrations during wood degradation (i.e., fatty acids and resin acids), and resulting the lower quality of final product (Josefsson, 2006 and Henriksson, 2006). The aim of this work is biopulping of sugarcane bagasse after physical treatments to achieve pulp of high order in the manufacture of paper.

Egypt. J. Microbiol. 49 (2014) 


\section{Materials and Methods}

Bagasse source

The Egyptian depithed sugarcane (Sacaharum officinurum) bagasse was obtained from ElNasr Company for sugar and pulp industry, Edfu, Egypt.

\section{Fungi used}

Ceriporiopsis subvernispora CZ-3 and Ophiostoma piliferum were obtained from the culture collection of Northern Regional Research Laboratory (NRRL), Department of Agriculture, Peoria, USA.

\section{Media used}

Peptone yeast extract medium (Jose et al., 2000) was used for fungi propagation and preservation. Minimal vitamin (MV) medium (Hatakka \& Pirhonen, 1985) was added to the bagasse to enhance their biodegradation by fungi.

\section{Propylene glycol (PG) pulping}

Pulping was carried out with or without pressure (using autoclave) as follows: Twenty five grams of depicted bagasse were firstly pretreated with $95 \%$ PG at liquor ratio of $1: 6(\mathrm{w} / \mathrm{v})$ in $1 \mathrm{~L}$ flask then heated at $60^{\circ} \mathrm{C}$ for $30 \mathrm{~min}$. Different concentrations of PG (80-100\%) and $0.29 \%$ of sulfuric acid were added to the filtrate of the liquor. The pulping time $(1-3 \mathrm{~h})$ and temperatures $\left(140-170^{\circ} \mathrm{C}\right)$ were adopted .The flasks were put in oil bath and heated under reflux for specified reaction time (1-3h). After pulping, the crude was filtered and washed successively with $80 \%$ aqueous acetone and water (Yasumitsu \& Yoshihiro, 1999).

\section{Physical factors affecting bagasse biodegradation by fungi}

Mesh size

Fifty grams from different bagasse mesh size (10-20) were placed in $3 \mathrm{~L}$ Erlenmeyer flask, the sterile bagasse were inoculated with standard $C$. subvernispora (as a model of an effective fungus) inoculum $(0.15 \mathrm{~g} \mathrm{CDW} / 10 \mathrm{ml})$ after adding $100 \mathrm{ml}$ of MV medium. The weight loss and acid perceptible polymeric lignin (APPL) were determined after 4 week at $27 \pm 1$.

\section{Extractive removal}

To remove the resins, fat sand waxes from bagasse, two physical methods were carried out: Boiling distilled water using soxhlet extraction apparatus and steaming by autoclave.

\section{Fungal treatment of bagasse}

After treating bagasse with the mentioned physical methods it was subjected to fungal treatments, either by single, mixed or consequence inoculum. Twentyfive grams of oven-dried bagasse (10 mesh size) were placed in 3-liter Erlenmeyer flask and autoclaved at $121^{\circ} \mathrm{C}$ for $20 \mathrm{~min}$. For the treatment with single or mixed cultures of $O$. piliferum and $C$. subvernispora, the sterilized bagasse was inoculated with $10 \mathrm{ml}$ of standard fungal inocula and incubated for 1-4 weeks at $27 \pm 1^{\circ} \mathrm{C}$. Concerning the two-stage culture the sterilized bagasse was treated with $O$. piliferum for different incubation periods (1,2,3 and 4 weeks) in the first stage of degradation at $27 \pm 1^{\circ} \mathrm{C}$. Samples were taken periodically every week and autoclaved at $121^{\circ} \mathrm{C}$ for $20 \mathrm{~min}$ to prevent the far effect of the 
fungus, then treated with $C$. subvermispora for 4 weeks at $27 \pm 1^{\circ} \mathrm{C}$ as a second stage. As a control biopulping it was carried out as previously mentioned but without any physical treatments. (Xinli et al., 2002 and Saad et al., 2008 ).

\section{Unbleached paper sheets preparation}

The pulps were beaten for different time intervals using Jokro beater with $6 \%$ pulp consistency at $150 \mathrm{rpm}$. The degree of freeness $\left({ }^{\circ} \mathrm{SR}\right)$ was measured according to the standard method by rising up the mixture to $2 \mathrm{~L}$ with water and disintegrated for $2 \mathrm{~min}$ in the standard disintegrator with the propeller running of $3000 \mathrm{rpm}$. Paper sheet were prepared from different pulps according to the Standard Canadian Association (SCA) standards using the SCA sheet former. In the apparatus, sheets of $165 \mathrm{~mm}$ diameter $\left(214 \mathrm{~cm}^{2}\right.$ surface) were formed. The sheets were then pressed for 4 min using hydraulic press. The pressure test was adjusted at $5 \mathrm{kgf} / \mathrm{cm}^{2}$ (Kilogram-force per square centimeter). The sheets were dried at $100^{\circ} \mathrm{C}$ for $2 \mathrm{~h}$ with a rotating drum and then were placed for conditioning to $65 \%$ relative humidity at $18-20^{\circ} \mathrm{C}$.

\section{Chemical analysis}

Weight loss of treated bagasse and APPL were determined according to the method recommended by Anthony et al. (1986). Hollocellulose, $\alpha$-cellulose and extractive content were determined according to the standard method suggested by Razak et al. (2013). The sheets properties were determined as follows: Brightness using a hunter-lab calorimeter, Kappa number according to TAPPI standard T-236, Degree of polymerization (DP) according to SCAN-CM 15:88, Tear factor according to the internal tearing resistance which was measured by a pendulum type instrument (Elmendrof Tearing Tester) and Breaking length $(\mathrm{km})$ was measured using a universal testing machine (Lloyd). Available at www. spectro. in /paper-Definition.html . Accessed on $3^{\text {th }}$ March . The experiments were carried out in triplicates and the values represented in this work are the arithmetical mean of the three replicates.

\section{Results and Discussion}

The amount of sugarcane bagasse in Egypt is abundant while the utilization is still limited. One of the alternatives for bagasse utilization is as pulp material. To minimize the waste from the pulping process, the effect of using a chemical process and a biopulping process (using $O$. piliferum and $C$. subvermispora SS-33) were studied and measured by the percentage of $\alpha$-cellulose content in bagasse pulp

Effect of pulping time and PG concentration on chemical bagasse composition

Data presented in Table 1 revealed that the favorable treatments were attained with $90 \%$ PG either under or without pressure at cooking temperature $150^{\circ} \mathrm{C}$ for $1 \& 2$ hour, respectively. The priority of these results was due to complete removal of rejects as well as low values of kappa number. The pulping using 90\% PG without pressure for $2 \mathrm{~h}$ was preceded, since it gave the highest hollocellulose and brightness also the lowest figures of pentosans and kappa no which were $93.77 \%, 37.8 \%, 9.01 \%$ and 22.45 , respectively. Increasing the cooking temperature to more than $150^{\circ} \mathrm{C}$ led to increase in kappa number by 1.25 and 1.51 fold at $160^{\circ} \mathrm{C}$ and $170^{\circ} \mathrm{C}$, respectively.

Egypt. J. Microbiol. 49 (2014) 
PULPING OF SUGARCANE BAGASSE ...

\begin{tabular}{|c|c|c|c|c|c|c|c|c|c|c|c|}
\hline \multirow{6}{*}{ 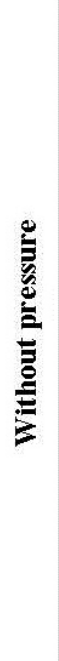 } & \multirow{2}{*}{\multicolumn{2}{|c|}{ ถूँ }} & $\sim$ & $\begin{array}{l}5 \\
\dot{8}\end{array}$ & $\stackrel{8}{0}$ & 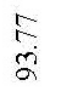 & $\frac{\circ}{\dot{\infty}}$ & 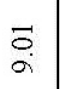 & 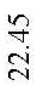 & $\begin{array}{l}8 \\
8 \\
8\end{array}$ & $\begin{array}{l}\infty \\
\infty \\
\infty\end{array}$ \\
\hline & & & - & $\begin{array}{l}\text { ते } \\
\ddot{y}\end{array}$ & 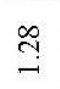 & $\begin{array}{c}\tilde{n} \\
\tilde{s}\end{array}$ & $\begin{array}{l}\underset{N}{2} \\
\ddot{\infty}\end{array}$ & $\begin{array}{l}m \\
\stackrel{m}{\varrho} \\
\stackrel{n}{2}\end{array}$ & 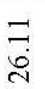 & $\begin{array}{l}8 \\
0 \\
\hat{n}\end{array}$ & $\begin{array}{l}\stackrel{8}{2} \\
\text { in }\end{array}$ \\
\hline & \multirow{6}{*}{ 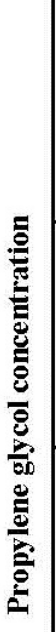 } & \multirow{2}{*}{ ڤू้ } & $\sim$ & $\stackrel{n}{m}$ & $\stackrel{\leftrightarrow}{i}$ & $\begin{array}{l}\text { Jे } \\
\text { کू }\end{array}$ & $\begin{array}{l}\stackrel{8}{0} \\
\infty \\
\infty\end{array}$ & $\begin{array}{l}\mathbb{J} \\
\stackrel{0}{0}\end{array}$ & $\begin{array}{l}8 \\
\text { : } \\
\text { i }\end{array}$ & $\begin{array}{l}8 \\
8 \\
\stackrel{0}{9} \\
=\end{array}$ & $\begin{array}{l}\stackrel{0}{0} \\
\cdots \\
m\end{array}$ \\
\hline & & & - & $\underset{\vec{m}}{\vec{\infty}}$ & $\stackrel{\Xi}{\rightarrow}$ & $\begin{array}{l} \pm \\
\stackrel{+}{\infty} \\
\infty\end{array}$ & 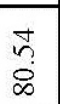 & $\stackrel{\curvearrowright}{\sigma}$ & $\begin{array}{l}\text { s. } \\
\text { iे }\end{array}$ & $\begin{array}{l}\stackrel{8}{\circ} \\
\stackrel{\pi}{\pi}\end{array}$ & $\underset{\text { di }}{\stackrel{\rho}{i}}$ \\
\hline & & \multirow{2}{*}{ 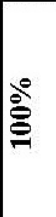 } & $\sim$ & $\begin{array}{l}\vec{n} \\
\dot{n} \\
m\end{array}$ & $\underset{\forall}{\stackrel{J}{*}}$ & $\begin{array}{l}\text { Fे } \\
\text { \& }\end{array}$ & \begin{tabular}{l}
0 \\
\multirow{2}{*}{} \\
$w$ \\
$\infty$
\end{tabular} & $\stackrel{\text { సે }}{=}$ & $\begin{array}{l}\text { 울 } \\
\text { ì. }\end{array}$ & $\begin{array}{l}\stackrel{8}{0} \\
\stackrel{0}{1}\end{array}$ & $\underset{m}{\stackrel{m}{m}}$ \\
\hline & & & -1 & $\begin{array}{l}\infty \\
\infty \\
\dot{m}\end{array}$ & $\begin{array}{l}\vec{\sigma} \\
\overrightarrow{0}\end{array}$ & $\begin{array}{l}8 \\
0 \\
\infty \\
\infty\end{array}$ & $\frac{n}{\hat{n}}$ & 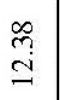 & 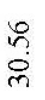 & $\begin{array}{l}8 \\
0 \\
0 \\
0 \\
\end{array}$ & $\begin{array}{l}\stackrel{?}{0} \\
\stackrel{\rho}{d}\end{array}$ \\
\hline \multirow{6}{*}{ 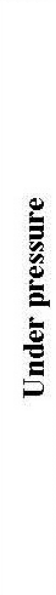 } & & \multirow{2}{*}{ ڤั } & $\sim$ & $\begin{array}{l}\vec{J} \\
\dot{J}\end{array}$ & $\begin{array}{l}8 \\
0\end{array}$ & $\stackrel{\infty}{\stackrel{\infty}{\infty}}$ & $\begin{array}{l}\vec{n} \\
0 \\
0\end{array}$ & $\begin{array}{l}\dot{a} \\
\dot{a}\end{array}$ & $\begin{array}{l}\infty \\
\infty \\
\dot{m}\end{array}$ & $\begin{array}{l}8 \\
\frac{8}{\infty} \\
\frac{\infty}{2}\end{array}$ & $\begin{array}{l}\stackrel{8}{0} \\
\infty \\
\infty\end{array}$ \\
\hline & & & -1 & $\begin{array}{l}\vec{n} \\
\ddot{q}\end{array}$ & $\stackrel{8}{8}$ & $\begin{array}{l}n \\
\infty \\
\infty \\
\infty\end{array}$ & $\begin{array}{l}\stackrel{0}{0} \\
\stackrel{8}{1}\end{array}$ & 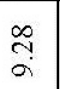 & $\begin{array}{l}\text { mे } \\
\text { ते }\end{array}$ & $\begin{array}{l}8 \\
8 \\
\infty \\
0\end{array}$ & i্ \\
\hline & & \multirow{2}{*}{ ஜूँ } & $N$ & $\begin{array}{l}\stackrel{m}{q} \\
\dot{q}\end{array}$ & 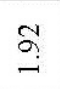 & $\begin{array}{l}\infty \\
\stackrel{\infty}{1} \\
\stackrel{\infty}{\infty}\end{array}$ & $\frac{n}{2}$ & $\stackrel{g}{a}$ & $\underset{\infty}{\vec{\infty}}$ & $\begin{array}{l}8 \\
8 \\
\text { ¿े }\end{array}$ & $\underset{\stackrel{9}{\sim}}{\stackrel{9}{N}}$ \\
\hline & & & - & $\stackrel{8}{\stackrel{8}{f}}$ & $\stackrel{\tilde{n}}{i}$ & $\begin{array}{l}\vec{a} \\
\tilde{\infty}\end{array}$ & $\begin{array}{l}\infty \\
\infty \\
2 \\
2\end{array}$ & $\begin{array}{l}\stackrel{g}{+} \\
\stackrel{0}{\circ}\end{array}$ & $\begin{array}{l}\dot{D} \\
\infty \\
m \\
m\end{array}$ & $\begin{array}{l}8 \\
8 \\
\frac{8}{0} \\
\end{array}$ & $\begin{array}{l}8 \\
\infty \\
\infty \\
\sim\end{array}$ \\
\hline & & \multirow{2}{*}{ 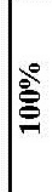 } & a & 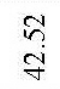 & $\stackrel{\leftrightarrow}{\mathrm{i}}$ & $\frac{8}{\infty}$ & $\stackrel{m}{m}$ & $\begin{array}{l}8 \\
0 \\
0\end{array}$ & $\frac{\tilde{r}}{\tilde{m}}$ & $\begin{array}{l}8 \\
\stackrel{8}{2} \\
\frac{1}{2}\end{array}$ & $\begin{array}{l}\stackrel{9}{0} \\
\stackrel{0}{0}\end{array}$ \\
\hline & & & - & $\underset{⿱ 亠 凶}{\stackrel{\infty}{f}}$ & $\begin{array}{l}\vec{a} \\
\vec{n}\end{array}$ & $\frac{\vec{\sigma}}{\dot{\infty}}$ & $\begin{array}{l}m \\
\stackrel{8}{\infty}\end{array}$ & $\stackrel{\infty}{\stackrel{\circ}{\Xi}}$ & $\begin{array}{l}\qquad b \\
b \\
\dot{m}\end{array}$ & $\begin{array}{l}8 \\
8 \\
8 \\
\alpha\end{array}$ & $\underset{\stackrel{8}{0}}{\stackrel{8}{4}}$ \\
\hline & & \multicolumn{2}{|c|}{$\stackrel{\Xi}{g} \widehat{\Xi}$} & & & & & & & & \\
\hline & & & & 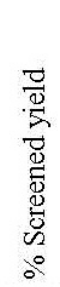 & $\begin{array}{l}\frac{n}{2} \\
\frac{0}{2} \\
\frac{2}{2} \\
0\end{array}$ & 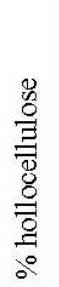 & $\begin{array}{l}0 \\
\% \\
0 \\
\Xi \\
\bar{\Xi} \\
0 \\
0\end{array}$ & 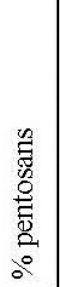 & 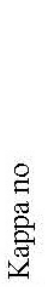 & 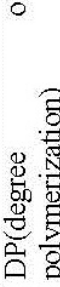 & 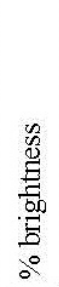 \\
\hline
\end{tabular}


Effect of bagasse mesh size on its biodegradation by C. subvernispora

Increasing the mesh size of bagasse from 10 to 20 led to increasing in the weight loss and APPL, which were $26.29 \%$ and $2.98 \%$, respectively (Fig.1). Therefore, the 10-mesh size fraction could be recommended as the proper size for bagasse pulping.

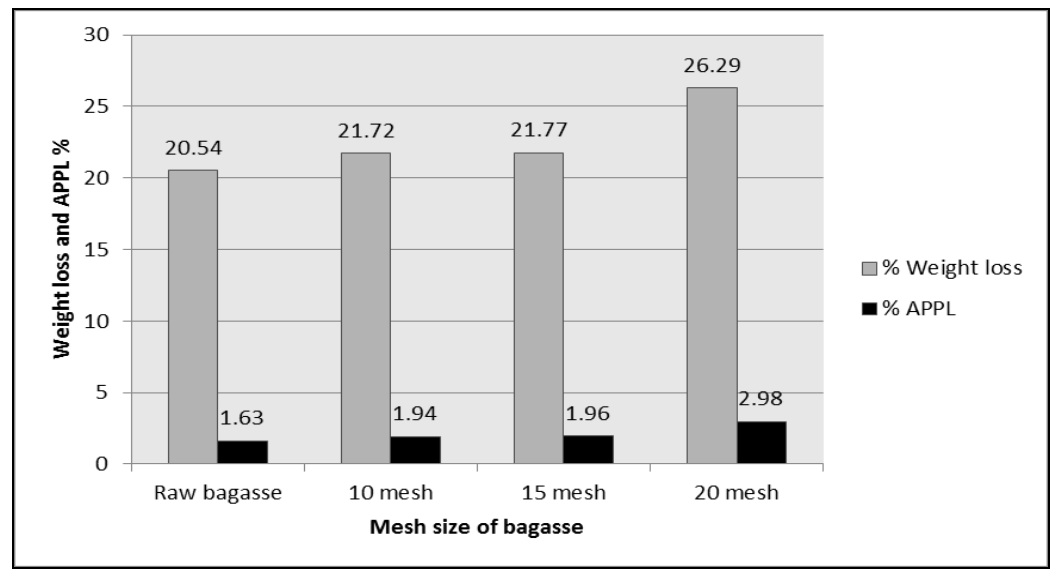

Fig.1. Effect of bagasse mesh size on weight loss \& APPL after treating by $C$. subvermispora.

Effect of bagasse treatment with $C$. subvernispora on chemical and physical properties of unbleached paper sheet

This experiment designed to compare between the effect of $C$. subvernispora inoculation applied on untreated or physicaly treated bagasse (steam \& boiled water), compared with chemically (PG 90\%) treated bagasse and the effect on the properties of unbleached paper sheets. The illustrated data in Fig. 2 revealed that the properties of unbleached chemical pulp and its paper sheet had low quality comparing to that recorded by biopulping either by prephysical treated or bagasse biopulp. It could be stated that using steam as physical pretreatment of bagasse biopulp was superior than the other treatments, since it gave the highest figure of yield being $43.72 \%$ and lowest kappa number being 15.18. Regarding the physical properties of unbleached paper sheets, data clearly show that the highest brightness $(43.9 \%)$, breaking length $(4.11 \mathrm{~km})$ and tear factor $(56.9)$ were attained by steam pretreatment on bagasse biopulping using $C$. subvernispora.

Effect of bagasse treatment with $O$. piliferum on chemical and physical properties of unbleached paper sheet

The treatment of bagasse with $O$. piliferum recorded in Table 2 revealed that no remarkable change could be detected either in figure of $\alpha-$ cellulose $\%$, pentosans $\%$ or DP. Whereas, screened yield percentage and kappa number decreased gradually during the incubation period till reached $36.15 \%$ and 20.06 respectively, after 4 weeks, i.e., reduced by 9.78 and $10.64 \%$, respectively, when compared with the chemical pulp treatment. Brightness $\%$ and tear factor also increased with about $3.15 \%$ and $4.74 \%$, respectively.

Egypt. J. Microbiol. 49 (2014) 

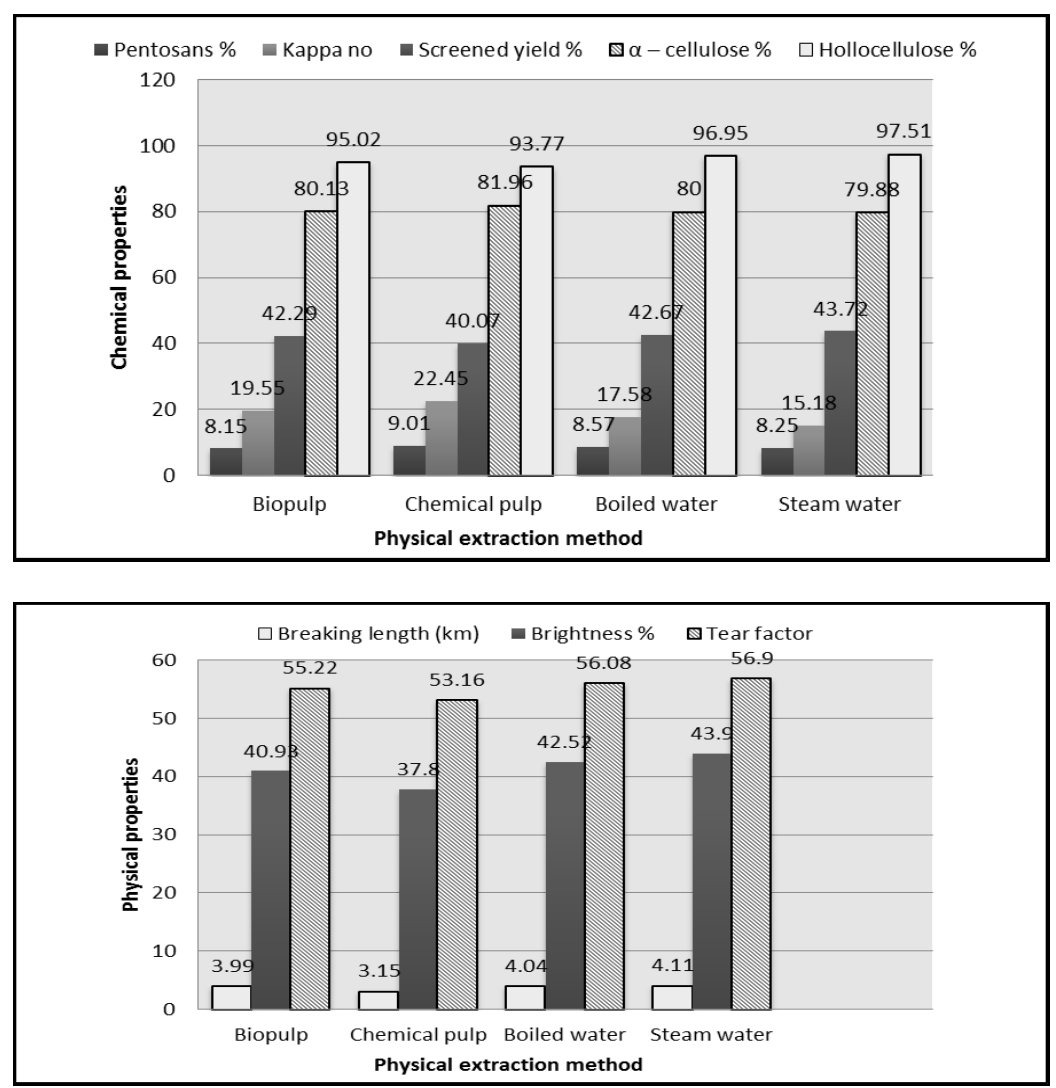

Fig. 2. Chemical and physical properties of unbleached paper sheets as influenced either by bagasse chemical pulping (PG 90\%) or C. subvermispora biopulping.

TABLE 2. Chemical and physical properties of unbleached paper sheets made from O. piliferum treated bagasse.

\begin{tabular}{|l|l|c|c|c|c|}
\hline \multirow{2}{*}{$\begin{array}{c}\text { Properties of UPS* } \\
\text { 1- Chemical properties }\end{array}$} & \multicolumn{5}{|c|}{ UPS* treated by O. piliferum } \\
\cline { 2 - 6 } & $\begin{array}{c}\text { Chemical } \\
(\mathbf{9 0 \%} \text { PG**) }\end{array}$ & $\mathbf{1}$ & $\mathbf{2}$ & $\mathbf{3}$ & $\begin{array}{c}\mathbf{4} \\
\text { (weeks) }\end{array}$ \\
\hline Screened yield \% & 40.07 & 37.33 & 36.72 & 36.42 & 36.15 \\
Hollocellulose \% & 93.77 & 93.82 & 93.99 & 94.55 & 94.71 \\
$\alpha-$ cellulose \% & 81.96 & 81.77 & 81.72 & 81.55 & 81.50 \\
Pentosans \% & 9.01 & 8.34 & 8.13 & 8.02 & 8.01 \\
Kappa no & 22.45 & 22.05 & 21.14 & 20.32 & 20.06 \\
DP*** & 1100 & 1099 & 1095 & 1084 & 1065 \\
2- Physical properties & & & & & \\
Brightness \% & 37.8 & 37.99 & 38.15 & 38.55 & 38.99 \\
Breaking length(km.) & 3.15 & 3.35 & 3.75 & 3.92 & 3.95 \\
Tear factor & 53.16 & 55.11 & 55.45 & 55.55 & 55.68 \\
\hline
\end{tabular}

$*$ = Unbleached paper sheets $\quad * *=$ propylene glycol $\quad * * *=$ degree of polymerization 
Unbleached paper sheets of bagasse as influenced by mixed culture of $O$. piliferum and C. subvermispora

The biodegradation of 10 mesh size bagasse was carried out by using a mixed culture of $O$. piliferum and $C$. subvermispora in $\mathrm{MV}$ medium at $27^{\circ} \mathrm{C}$ for different incubation periods (1-4 weeks). Data given in Table 3 show that the $\alpha$ cellulose and pentosans \% contents of biopulped bagasse were decreased gradually during incubation period of this biological treatment than that present in chemical pulping to reach the minimum value at the end of incubation period being $77.08 \%$ and $4.11 \%$, respectively. On the other hand, the biological treatment by mixed fungal cultures led to loss of 5.95 and $54.38 \%$ of $\alpha$-cellulose and pentosans respectively, as compared by chemical treatment, whereas decrease in kappa number and increase in brightness by 44.77 and $21.58 \%$, respectively were noted. Also, data indicate that using the treatment with mixed culture for one week gave the highest value of screened yield \%, breaking length, and tear factor being $43.21 \%, 4.99 \mathrm{~km}$ and $59.0 \%$ respectively.

TABLE 3. Chemical and physical properties of unbleached paper sheets as influenced either by baggasse chemical pulping (PG 90\%) or mixed culture of $O$. piliferum and $C$. subvermispora biopulping.

\begin{tabular}{|l|c|c|c|c|c|}
\hline \multirow{2}{*}{$\begin{array}{c}\text { Properties of UPS* } \\
\text { 1- Chemical properties }\end{array}$} & $\begin{array}{c}\text { UPS* treated by } \text { O. piliferum and C. } \\
\text { Chemical } \\
\text { (90\% PG **) }\end{array}$ & $\mathbf{1}$ & $\mathbf{2}$ & $\mathbf{3}$ & $\begin{array}{c}\mathbf{4} \\
\text { (week) }\end{array}$ \\
\hline Screened yield \% & 40.07 & 43.21 & 39.29 & 37.05 & 35.50 \\
Hollocellulose \% & 93.77 & 97.68 & 97.72 & 97.91 & 97.93 \\
$\alpha-$ cellulose \% & 81.96 & 81.09 & 80.18 & 77.12 & 77.08 \\
Pentosans \% & 9.01 & 7.65 & 6.61 & 4.51 & 4.11 \\
Kappa no & 22.45 & 14.15 & 12.44 & 12.42 & 12.40 \\
DP & 1100 & 1009 & 1005 & 895 & 892 \\
2- Physical properties & & & & & \\
Brightness \% & 37.8 & 45.25 & 45.95 & 45.96 & 45.96 \\
Breaking length(km) & 3.15 & 4.99 & 3.92 & 2.43 & 2.05 \\
Tear factor & 53.16 & 59 & 56.12 & 44.66 & 44.62 \\
* Unbleached paper sheets & $* *$ Propylene glycol & &
\end{tabular}

Unbleached paper sheets of bagasse as influenced by consequent two-stage degradation by $O$. piliferum and $C$. subvermispora

Data of chemical and physical properties of paper hand sheets were recorded in Table 4 revealed that the highest value of breaking length and tear factor were attained when $O$. piliferum was incubated for one week as first stage of bagasse degradation followed by 4 weeks of $2^{\text {nd }}$ stage inoculation. Whereas, the highest screened yield \% was observed after the first week of incubation period. Moreover, $\alpha$-cellulose $\%$ and pentosans $\%$ recorded the lower figures after the end in all experiments treatments than that obtained by chemical pulping treatment. 
TABLE 4. Chemical and physical properties of unbleached paper sheets with two stage of bagasse degradation by $O$. piliferum and $C$. subvermispora.

\begin{tabular}{|c|c|c|c|c|c|c|c|}
\hline \multirow{4}{*}{ Properties of UPS* } & \multirow{3}{*}{\begin{tabular}{|c|} 
Fungus \\
O.P** \\
\end{tabular}} & \multirow{3}{*}{\begin{tabular}{c|} 
Stage \\
$1^{\text {st }}$ \\
\end{tabular}} & \multicolumn{4}{|c|}{ n by 0 . pulferum and c. subve } & \multirow{4}{*}{$\begin{array}{c}\text { Chemical } \\
\text { pulp }\end{array}$} \\
\hline & & & \multicolumn{4}{|c|}{ Incubation period (week) } & \\
\hline & & & 1 & 2 & 3 & 4 & \\
\hline & C.S $* * *$ & $2^{\text {nd }}$ & \multicolumn{4}{|c|}{ Four weeks } & \\
\hline \multicolumn{8}{|l|}{ 1- Chemical properties } \\
\hline Screened yield $\%$ & & & 43.13 & 37.68 & 35.84 & 32.39 & 40.07 \\
\hline Hollocellulose \% & & & 96.25 & 96.61 & 96.85 & 96.85 & 93.77 \\
\hline$\alpha-$ cellulose $\%$ & & & 80.44 & 77.74 & 76.73 & 75.82 & 81.96 \\
\hline Pentosans \%\% & & & 8.15 & 7.77 & 7.23 & 6.55 & 9.01 \\
\hline Kappa no & & & 17.00 & 14.55 & 1423 & 14.15 & 22.45 \\
\hline DP & & & 1007 & 899 & 857 & 845 & 1100 \\
\hline \multicolumn{8}{|l|}{ 2- Physical properties } \\
\hline Brightness \% & & & 42.85 & 44.77 & 44.65 & 44.88 & 37.8 \\
\hline $\begin{array}{l}\text { Breaking } \\
\text { length }(\mathrm{km} .)\end{array}$ & & & 4.95 & 2.13 & 1.77 & 1.52 & 3.15 \\
\hline Tear factor & & & 56.85 & 31.53 & 25.23 & 23.03 & 53.16 \\
\hline
\end{tabular}

Scanning electron microscope (SEM) of unbleached bagasse pulp influenced by fungal pretreatment

Scanning electron micrographs from the pulp are shown in Fig. 3. From comparing the hand sheets made from the biologically treated with mixed culture of $O$. piliferum and $C$. subvermispora SS-33 at one stage cultivation, C.subvermispora SS-33 in single culture, and untreated chemical pulp, it could be observed that the treated fibers exhibit a cleaner surface and an apparent high flexibility and conformability, which would contribute to good bonding. The mentioned results were more visible in the mixed one stage fungal culture treatment.

Xinli \& Kokki (2002) reported that using a marine fungus, Phlebia sp. MG60 and three white-rot fungi were incubated with whole sugarcane bagasse (WSB) resulted in more than $50 \%$ of lignin degraded and less than $10 \%$ of the holocellulose was lost. They predicted also that the most efficient utilization of bagasse fiber might be employed as the raw material in the pulp and paper industry after biopulping with Phlebia sp.

Fermentation time, fungal mycelium load and pretreatment scale were studied in the fungal treatment, and the best conditions were 15 days with $250 \mathrm{mg} \mathrm{kg}^{-1}$ fungal mycelium per straw weight causing high lignin decomposition. At the largest scale tested (50 g straw) lignin degradation exceeded cellulose degradation by 2.4-fold (Saad et al., 2008). Seven strains of Panus tigrinus were grown, without any additional carbon source, on sugarcane bagasse for 10 days 
in a semi-solid state fermentation. The production of ligninases by fungi were correlated with the efficiency of delignification process in bagasse after organosolv pulping with aqueous acetic acid. Analysis of decayed sugarcane bagasse by FTIR indicated a correlation between lignin modification and pulp properties in some strains, in such a way that the more the lignin modifies, the more the pulp properties improve (Adilson et al., 1998).
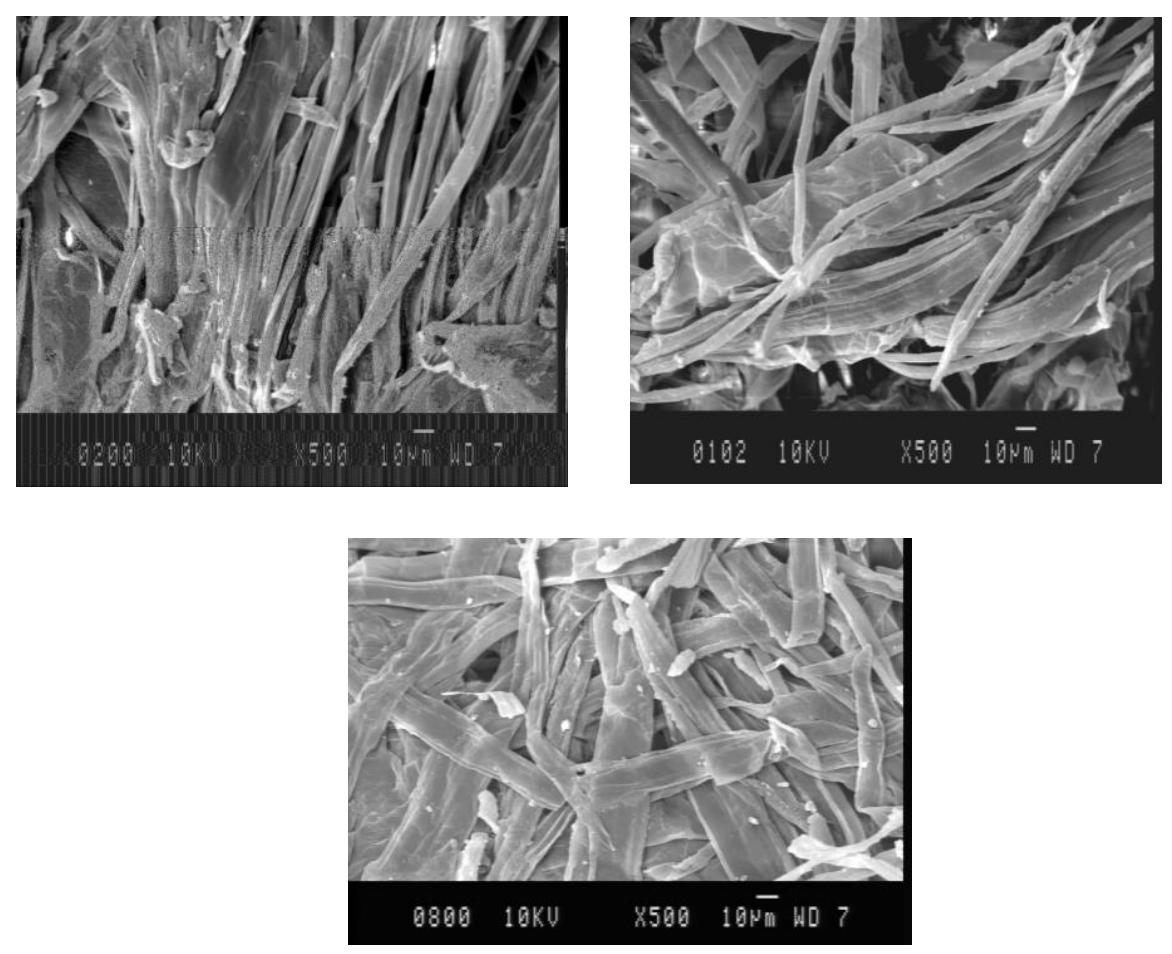

Fig. 3. Scanning electron photographs of (A): Unbleached bagasse chemical pulp (B) $\&$ (C) Bagasse treated with $O$. piliferum and $C$. subvermispora, respectively.

Antaresti et al. (2008), reported that in the chemical process of bagasse, the nitric acid concentration and the reaction time were varied. The pulping process was conducted at constant temperature of $102^{\circ} \mathrm{C}$ and the mixture was agitated at $900 \mathrm{rpm}$. The highest percentage of $\alpha$-cellulose content in pulp was $79.28 \%$, obtained at the concentration of $3.5 \%$ for a reaction time of $3.5 \mathrm{~h}$. At higher concentrations and longer cooking times, the $\alpha$-cellulose decreased due to the cellulose degradation. In the biopulping process, the incubation temperature was kept at $30^{\circ} \mathrm{C}$. The highest percentage of $\alpha$-cellulose was $65.80 \%$ obtained at an incubation time of 25 days. When compared to nitric acid pulping, biopulping is less efficient. However it has one advantage that it only uses a small amount of chemicals and, therefore, creates less pollutants. 
Biopulping is a type of industrial biotechnology. It uses a type of natural fungus to convert wood chips to paper pulp. The main processes for paper production that are currently in use are mechanical and chemical. Biopulping provides a solution to the problems of chemical and mechanical paper production. It uses fungi present in natural wood decay to alter the lignin in the cell walls of the wood, which therefore "softens" the wood chips. Since the wood is already softened when it goes to the final steps to be made into paper, the remaining steps of the process require less energy and do not pollute the air since there is no need for chemicals.

Akhtar et al. (2000) reported that the mechanical pulping process is electrical energy intensive and results in low paper strength. Biomechanical pulping, defined as the fungal treatment of lignocellulosic materials prior to mechanical pulping, has shown at least $30 \%$ savings in electrical energy consumption, and significant improvements in paper strength properties compared to the control at a laboratory scale. In an effort to scale-up biomechanical pulping to an industrial level, 50 tons of spruce wood chips were inoculated with the best biopulping fungus in a continuous operation and stored in the form of an outdoor chip pile for 2 weeks. The pile was ventilated with conditioned air to maintain the optimum growth temperature and moisture throughout the pile paper strength properties the control and fungus-treated chips were refined through a thermomechanical pulp mill (TMP) producing lightweight coated paper. The fungal pretreatment saved 33\% electrical energy and improved significantly compared to the control. Since biofibers were stronger than the conventional TMP fibers, we were able to reduce the amount of bleached softwood kraft pulp by at least $5 \%$ in the final product. Fungal pretreatment reduced brightness, but brightness was restored to the level of bleached control with $60 \%$ more hydrogen peroxide.

Results revealed that the properties of unbleached chemical pulp and its paper sheet had low quality comparing to that recorded by biopulping either by fungal treatment alone or companied with prephysical treatment. These results are in line with those obtained by Bajpai et al. (2004) who found that treatment of depithed bagasse with Ceriporiopsis subvernispora reduced the kappa number by $10-15$.

Comparing the properties of paper hand sheets made from both treatments of biopulping either in mixed fungal culture or separately (two stage), it could be stated that using both Ophiostoma apiliferum and C. subvermispora SS-33 as mixed culture for bagasse degradation in one stage was the best biotreatment. Moreover, this treatment increased brightness, breaking length, and tear factor compared to biopulping by two stage degradation, biopulping of steam extraction and chemical pulping, respectively.

Scanning electron microscope images revealed that the treated fibers exhibit a cleaner surface and an apparent high flexibility and conformability, which would contribute to good bonding, were more visible in the mixed fungal culture as one 
stage. These results may be due to cell wall swelling, softening, and collapse of the cell structure as obtained from previous studies by Gamal et al. (2000).

Messner \& Srebotnik (1994) stated that treatment of wood chips with lignindegrading fungi prior to pulping has been shown to have great potential for mechanical as well as chemical pulping on a laboratory scale. C. subvermispora, when grown on aspen or loblolly pine for 4 weeks, was found to be superior to other fungi. On aspen there was an energy savings of $47 \%$, and an increase in burst and tear indices of $22 \%$ and $119 \%$, respectively. With loblolly pine, energy savings amounted to $37 \%$, while burst and tear indices increased by $41 \%$ and $54 \%$, respectively. The weight loss was only $6 \%$, but a decrease in optical properties had to be accepted. Wall et al. (1996) showed that the use of O.piliferum for hardwood treatment resulted in extractive degradation, improvement in chemical pulping efficiency and reduction of kappa number up to $29 \%$.

Messner \& Srebotnik (1994) stated that information obtained by immunoelectron microscopy and differential staining led to the conclusion that the biopulping effect obtained after 2 weeks of incubation cannot be explained by the direct action of enzymes on lignin or polysaccharides. Instead, a low molecular mass agent is considered to be responsible for the biopulping effect. These results have changed the aims of biopulping from an emphasis on removing the bulk of lignin to an emphasis on a short-term process, lasting 2 weeks and yielding a low mass loss.

Hosseinpour et al. (2010) recorded that the chemimechanical pulping (CMP) of canola straw can be conducted using different dosages of sodium sulfite and sodium hydroxide. The results showed that, by a mild chemical pretreatment (4$12 \%$ (wt.) $\mathrm{NaOH}$ and $8-12 \%$ (wt.) $\mathrm{Na}_{2} \mathrm{SO}_{3}$ ), the pulp brightness reached almost $40 \%$ ISO and the strength properties were comparable to those of bagasse CMP and of wheat straw CMP.

\section{References}

Adilson, R., Gonçalves, Elisa E. and Benar, Priscila (1998) Evaluation of Panus tigrinus in the delignification of sugarcane bagasse by FTIR-PCA and pulp properties. Elsevier Science B.V.

Akhtar, M., Scott, G.M., Swaney, R.E. and Shipley, D.F. (2000) Biomechanical pulping: a mill-scale evaluation. Resources, Conservation and Recycling, 28, 241-252.

Antaresti, Y.S., Setiyadi, H.W. and Yogi, Y.P. (2008) The effect of chemical and biopulping process on bagasse pulp. Developments in Chemical Engineering and Mineral Processing, 13, 639-644.

Anthony, L., Pometto, A.L. and Crrawford, D.L. (1986) Catabolic fate of Streptomyces viridosporous T7A-produced acid precipitable polymeric lignin upon

Egypt. J. Microbiol. 49 (2014) 
incubation with ligininolytic Streptomyces species and Phanerochaete chrysosporium. Appl. Environ. Microbiol. 51, 171-179.

Bajpai, P., Mishra, S. P., Mishra, O. P., Kumar, S., Bajpai, P. K. and Singh, S. (2004) Biochemical Pulping of Bagasse. Biotechnology Progress, 20, 1270- 1272.

Ferraz, A., Mendonca, R. and Ailva, F. (2000a) Organosolv delignification of whiteand brown-rotted Eucalyptus frandis hardwood. J. Chem. Technol. Biotechnol. 75, 1824.

Ferraz, A., Roduiguez, J., Freer, J. and Baeza, J. (2000b) Formic acid/acetone organosolv pulping of white-rotted Pinus radiate softwood. J. Chem. Technol. Biotechnol. 75,1190-1196.

Gamal, Rawia F., Abdelhady, H.A., Mansour, O.Y. and Hassan, E.A. (2000) Factors affecting fungal pretreatment of bagasse for thermomechanical pulping. Annal of Agric. Sc. Moshtohor. 38, 833-849.

Gonçalves, A.R., Moriya, R.Y., Oliveira, L.R. and Saad, M.B. (2008) Xylanase recycling for the economical bioleaching of sugarcane bagasse and straw pulps. Enzyme and Microbial Technology, 43, 157-163.

Hatakka, A.I. and Pirhonen, I.I. (1985) Cultivation of wood- rotting fungi on agricultural lignocellulosic materials for the production of crude protein. Agricultural Wastes, 12, 81-97.

Henriksson, G. (2006) Controlled seasoning of scots pine chips using an albino strain of Ophiostoma. Ind. Eng. Chem. Res. 45 (7), 2374-2380.

Hosseinpour, R., Fatehi, P., Latibari, A.J., Ni, Y. and Sepiddehdam, S.J. (2010) Canola straw chemimechanical pulping for pulp and paper production. Bioresource Technology, 101, 4193-4197.

José, D., Frank, W., Claassen, G.L., Teris, A.V.B., Joannes, B.P., Wijnberg, A. and Reyes, S.A. (2000) Degradation and detoxification of softwood extractives by sapstain fungi. Bioresource Technology, 71, 13-20.

Josefsson, P., Nilsson, F., Sundström, L., Norberg, C., Lie, E., Björklund, J.M. and Henriksson, G. (2006) Controlled seasoning of scots pine chips using an albino strain of Ophiostoma. Ind. Eng. Chem. Res. 45 (7), 2374-2380.

Messner, K. and Srebotnik, E. (1994) Biopulping: An overview of developments in an environmentally safe paper-making technology. FEMS Microbiology Reviews, 13,351364.

Razak, W., Mohd Tamizi, M., Mahmud Sudin and Aminuddin, M. (2013) Extractives, holocellulose, $\alpha$-cellulose, lignin and ash contents in cultivated tropical bamboo gigantochloa brang, G. levis, G. scortechinii and G. wrayi . Current Research Journal of Biological Sciences, 5(6), 266-272. 
Saad, M.B.W., Oliveira, L.R.M., Cândido, R.G., Quintana, G., Rocha, G.J.M. and Gonçalves, A.R. (2008) Preliminary studies on fungal treatment of sugarcane straw for organosolv pulping. Enzyme and Microbial Technology, 43(2), 220- 225.

Yasumitsu, U. and Yoshihiro, S. (1999) Polyhydric alcohol pulping at atmospheric pressure: an effective method for organosolv pulping of softwoods. Holzforschung, 53(4), 411-415.

Xinli, Ryuichito Kondo and Kokki, S. (2002) Biodegradtion of sugarcane bagasse with marine fungus Pblebia sp.MG-60. J. Wood Science, 48 (2), 159-162.

Wall et al. (1996) Cited in Environmentally Friendly Production of Pulp and Paper John Wiley \& Sons, Mar 21, 2011 .

(Received 24/2/2014;

accepted 29/4/2014) 


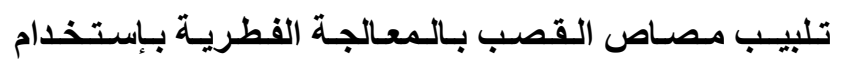

Ceriporiopsis subvermispora SS-33, Ophiostoma piliferum

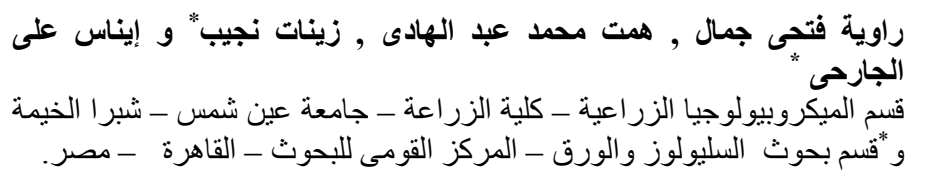

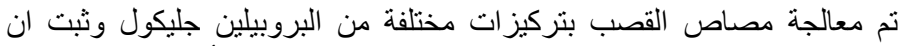

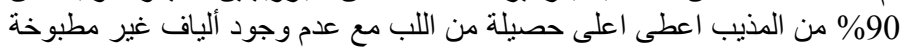

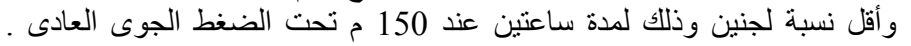

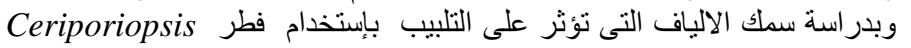

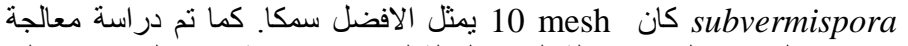

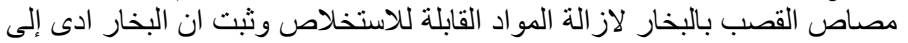

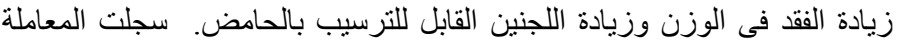

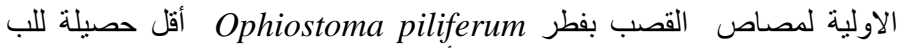

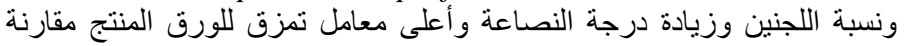

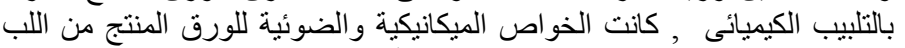

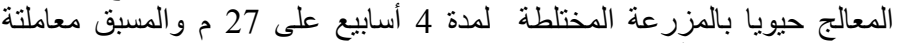

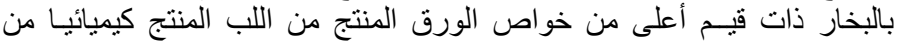

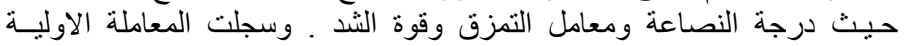

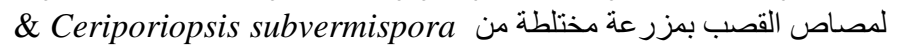

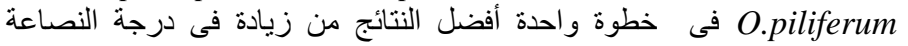

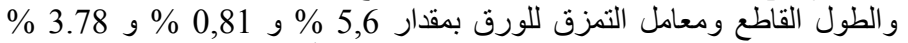

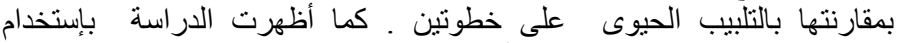

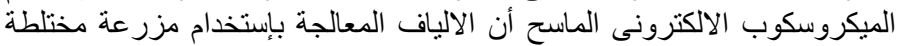

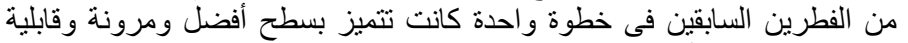

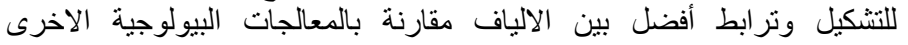

المستخدمة. 